Agritech, 38 (2) 2018, 133-139

\title{
Efek Pretreatment Microwave-NaOH Pada Tepung Gedebog Pisang Kepok terhadap Yield Selulosa
}

\author{
The Effect of Microwave-NaOH Pretreatment on Kepok's Petiole Flour to The Cellulose Yield \\ Dewi Maya Maharani*, Khulafaur Rosyidin
}

\author{
Jurusan Keteknikan Pertanian, Fakultas Teknologi Pertanian, Universitas Brawijaya, \\ Jl. Veteran, Malang 65145, Indonesia \\ Email: maya_maharani@ub.ac.id
}

Tanggal submisi: 21 Januari 2016; Tanggal penerimaan: 23 Maret 2018

\begin{abstract}
ABSTRAK
Sumber karbon dalam gula untuk dikonversi menjadi bioetanol banyak mengalami perkembangan, mulai dari sumber bioetanol generasi satu, generasi dua dan generasi tiga. Gedebog pisang merupakan salah satu limbah berlignoselulosa generasi dua yang potensial di Indonesia dan memiliki kandungan selulosa tinggi yang dapat dimanfaatkan sebagai bahan baku produksi bioetanol. Penelitian ini bertujuan untuk mengetahui pengaruh gelombang microwave terhadap kandungan selulosa tepung (gedebog) pisang kepok dan mengetahui pengaruh lama pretreatment serta perbandingan massa bahan dengan volume pelarut $\mathrm{NaOH}$ terhadap kandungan selulosa tepung (gedebog) pisang kepok pada proses pretreatment yang dimanfaatkan untuk produksi bioetanol. Gedebog pisang ukuran 60 mesh sebanyak $20 \mathrm{~g}$ dilarutkan pada larutan $\mathrm{NaOH} \mathrm{0,5} \mathrm{M} \mathrm{dengan} \mathrm{variasi} \mathrm{volume} \mathrm{pelarut} 150 \mathrm{~mL}, 200 \mathrm{~mL}$, dan $250 \mathrm{~mL}$, selanjutnya diberi perlakuan (pretreatment) gelombang microwave dengan variasi waktu 20, 30 dan 40 menit. Pada hasil uji lanjut Annova menyatakan bahwa variabel waktu memberikan pengaruh nyata terhadap kandungan selulosa sedangkan interaksi antara variabel dan volume tidak memberikan pengaruh nyata terhadap kandungan selulosa. Selulosa merupakan senyawa yang akan dikonversi lebih lanjut menjadi glukosa. Sehingga pada penelitian ini memilih penurunan selulosa terendah yaitu menjadi $350,20 \mathrm{mg} / \mathrm{g}$ akibat pretreatment microwave- $\mathrm{NaOH}$ dengan rendemen 93,10\% pada perlakuan massa bahan dengan volume pelarut $20 \mathrm{~g}: 250 \mathrm{~mL}$ dengan waktu 30 menit.
\end{abstract}

Kata kunci: Selulosa; microwave; gedebog pisang; pretreatment

\begin{abstract}
Carbon sources in the form of sugar to be converted into bioethanol are rapidly developed, they are so called as the first generation, the second generation, and the third generation. The petiole of banana is the second generation of lignocellulose which is a waste and potential in Indonesia to be used as the raw material of bioethanol production. This study aimed to determine the effect of the microwave to the content of petiole 's flour of "gepok" varieties and to know the effect of pretreatment time as well as the ratio of petiole mass to the resulted flour with the solvent of $\mathrm{NaOH}$ for bioethanol production. The $20 \mathrm{~g}$ of petiole with the size of 60 mesh was dissolved into $\mathrm{NaOH} 0.5 \mathrm{M}$ with the variation of solvent volume $150 \mathrm{~mL}, 200 \mathrm{~mL}$ and $250 \mathrm{~mL}$ then was pretreated with microwave as long as 20, 30, and 40 minutes. Annova resulted that time variable affected the cellulose content however the volume didn 't. Cellulose is a compound which is going to be converted into glucose. Hence, in this study, the lowest decrease of cellulose 350,20 $\mathrm{mg} / \mathrm{g}$ was chosen from the microwave pretreatment with a yield of $93,10 \%$ at $20 \mathrm{~g}: 250 \mathrm{~mL}$ for 30 minutes.
\end{abstract}

Keywords: Cellulose; microwave; petiole; pretreatment

\section{PENDAHULUAN}

Bahan Bakar Minyak (BBM) dari fosil merupakan sumberdaya alam yang tidak dapat diperbaharui, artinya pengadaan sumberdaya alam ini membutuhkan waktu yang sangat lama. Namun keadaan yang seperti ini tidak seimbang dengan konsumsi BBM yang terus meningkat.

Sebenarnya keberadaan BBM dapat disubstitusi dengan bioenergi seperti jenis bensin yang dapat disubstitusi ataupun dicampur dengan bahan baku lain yang lebih ramah lingkungan dan pengadaannya membutuhkan waktu relatif cepat yaitu bioetanol. Karakteristik dari bioetanol ini memiliki titik didih normal $78,4^{\circ} \mathrm{C}$ dan tidak berwarna (Rohmadi dan Amalia, 2010). Nama bioetanol sendiri diambil karena proses pembuatannya dari 
biomassa yang memanfaatkan sumber gula-gula sederhana untuk bisa difermentasi oleh bakteri fermentasi dan menghasilkan alkohol (bioetanol).

Sumber karbon dalam gula yang diperoleh dari biomassa untuk dikonversi menjadi bioetanol banyak mengalami perkembangan, mulai dari sumber bioetanol generasi satu yaitu dari sumber gula-gula sederhana yang langsung bisa difermentasi menjadi bioetanol seperti tepung ubi kayu, nira batang dari sorgum manis, molase (tetes tebu), nira aren, nira kelapa atau dari tanaman palma lain ataupun bahan yang bergula atau berpati lainnya seperti sagu (Prastowo dan Richana, 2014), patipatian seperti umbi kimpul juga dapat dimanfaatkan sebagai bahan baku produksi bioetanol (Sukaryo dan Hargono., 2013), kemudian generasi II dari lignoselulosa, seperti jerami, sekam, tandan kosong kelapa sawit, bagas tebu, kayu-kayuan, rumput (Prastowo dan Richana, 2014) dan tongkol jagung dengan kandungan selulosa yang cukup tinggi sehingga dapat digunakan sebagai sumber pembuatan bioetanol (Rasubala dkk., 2013) serta generasi III yang mengacu kepada pembuatan biofuel dari hasil panen budidaya algae (Prastowo dan Nur, 2014).

Sumber bioetanol dari generasi I dan III masih banyak menimbulkan pertentangan khususnya yang berkaitan dengan sumber bahan pangan akan saling bersaing, misal dari sumber pati dan alga sebagai sumber protein sel tunggal (PST), dibandingkan dengan sumber bioetanol dari generasi II yang tergolong limbah lignoselulosa. Menurut Anindyawati (2009), limbah industri dan pertanian dapat digunakan sebagai bahan produksi bioetanol seperti limbah pabrik gula, tandan kelapa sawit, kayu dan batang pisang (gedebog). Limbah tersebut terdapat kandungan lignoselulosa yang berlimpah dan belum digunakan maksimal serta dapat menjadi pertimbangan karena tidak bersaing dengan pangan. Komponen bahan lignoselulosa sangat kompleks, maka penanganan untuk produksi bioetanol harus melalui beberapa tahapan.

Keberadaan selulosa banyak sekali di bumi termasuk di Indonesia. Selulosa ini masih terikat kuat dengan polimer lain yaitu hemiselulosa dan lignin, ketiga polimer ini yang membentuk struktur dari biomasa. Pembuatan bioetanol dari generasi II ini harus melalui beberapa tahap yang penting karena substrat yang akan difermentasi adalah gula-gula sederhana untuk bisa dikonversi menjadi bioetanol. Sedangkan untuk mendapatkan gula-gula sederhana dari biomasa berlignoselulosa ini harus melalui beberapa proses agar didapatkan selulosa dari dalam lignin dan hemiselulosa. Tahap ini harus melalui proses pretreatment untuk mendapatkan selulosa kemudian selulosa harus diputus rantai panjangnya melalui proses hidrolisis untuk mendapatkan gula sederhana.

Pretreatment merupakan proses awal untuk mendapatkan selulosa dari biomasa serta banyak metode yang bisa dipakai baik secara bioproses yaitu enzimatis maupun secara katalis kimia baik asam atau basa. Menurut Seftian dkk. (2012), bahwa pretreatment biomassa pada bahan berlignoselulosa harus dilakukan agar didapatkan hasil tinggi karena bertujuan untuk membuka struktur dari lignoselulosa, agar polimer selulosa lebih mudah diakses oleh enzim yang memecah polimer polisakarida tersebut menjadi monomer gula sederhana. Kalau tidak ada pretreatment maka selulosa akan sulit dihidrolisis menjadi gula karena lignin masih sangat kuat melindungi polimer selulosa.

Menurut Dehani dkk. (2013), pretreatment lignoselulosa jerami padi menggunakan bantuan gelombang mikro berdaya 950 watt dan pelarut $\mathrm{NaOH}$ $0,5 \mathrm{M}$ pada waktu 40 menit dengan ukuran bubuk jerami 100 mesh dapat meningkatkan kadar selulosa jerami padi menjadi $42,32 \%$ yaitu dari $30,38 \%$ menjadi $72,70 \%$ dan menurunkan kadar lignin $4,27 \%$ yaitu dari 7,93\% menjadi 3,66\%. Gelombang mikro ini memiliki kemampuan dalam memecah struktur polimer dari lignoselulosa. Kemudian menurut hasil penelitian Elwin (2014), melakukan pretreatment lignoselulosa menggunakan bahan eceng gondok juga menggunakan bantuan gelombang mikro berdaya 700 watt selama 30 menit dan pelarut $\mathrm{NaOH} 2 \mathrm{M}$ dapat meningkatkan yield selulosa dari $56 \%$ menjadi $68,27 \%$ dan menurunkan lignin dari $12,01 \%$ menjadi $11,50 \%$. Penelitian Sukowati dkk. (2014) melakukan pretreatment kulit pisang menggunakan $\mathrm{NaOH} 1 \mathrm{M}$ pada suhu $121^{\circ} \mathrm{C}$ autoclave selama 15 menit dapat menurunkan kandungan lignin dari $21,29 \%$ menjadi $17,20 \%$ dan menaikkan selulosa dari $14,56 \%$ menjadi $29,29 \%$. Sedangkan penggunaan bantuan gelombang mikro dan pelarut $\mathrm{NaOH}$ (Natrium Hidroksida) selama ini masih sedikit dilakukan pada pretreatment tepung (gedebog) pisang. Oleh karena itu, penelitian ini menggunakan bantuan gelombang mikro (microwave) dan pelarut $\mathrm{NaOH}$ dalam proses pretreatment tepung (gedebog) pisang kepok untuk mengetahui yield selulosa. Penelitian ini menggunakan bahan dasar tepung (gedebog) pisang karena menurut Kardono dkk. (2010), bahwa kandungan selulosa tepung (gedebog) pisang mencapai $61,74 \%$ serta bahan ini tergolong limbah yang belum termanfaatkan dan jumlahnya yang banyak.

Penelitian ini bertujuan untuk mengetahui pengaruh gelombang microwave terhadap kandungan selulosa tepung (gedebog) pisang kepok, mengetahui lama pretreatment dan perbandingan massa bahan dengan volume pelarut $\mathrm{NaOH}$ terhadap perubahan kandungan selulosa tepung (gedebog) pisang kepok pada proses pretreatment produksi bioetanol.

\section{METODE PENELITIAN}

\section{Bahan}

Bahan utama dalam penelitian ini adalah (gedebog) pisang kepok atau bagian batang yang beruas-ruas dari pisang kepok. Pisang kepok ini didapat dari kebun milik warga RT 04 RW 02 Desa Sumberjo Jombang. Selain itu digunakan $\mathrm{NaOH}$ sebagai pelarut perlakuan untuk membantu merusak struktur lignoselulosa. 


\section{Alat}

Alat yang digunakan pada penelitian ini adalah microwave, blender, ayakan 60 mesh, oven dan pisau.

\section{Rancangan Percobaan}

Pisang kepok yang sudah ditebang dipisahkan dari jantung dan bonggolnya untuk diambil bagian kulit pisang (bagian beruas-ruas) kemudian diiris kecil-kecil sekitar 1 $\mathrm{cm}$ (rajang). Setelah diiris kecil-kecil, bahan kemudian dicuci sampai bersih untuk menghilangkan kotoran dan getah yang tersisa dan diblender untuk memperluas permukaannya. Setelah itu disaring dan dijemur bagian padatan selama 24 jam dan dioven pada suhu $105^{\circ} \mathrm{C}$ untuk mengurangi kadar air sampai $12 \%$, yang mana mikroorganisme dan jamur tidak dapat tumbuh sehingga tidak terjadi pembusukan bahan selama penyimpanan. Setelah dioven, bahan diayak menggunakan ayakan 60 mesh.

Penelitian ini menggunakan faktor lama pretreatment dan perbandingan massa bahan : volume pelarut $\mathrm{NaOH}$, dari faktor ini agar didapatkan perlakuan terbaik dalam proses pretreatment tepung (gedebog) pisang untuk produksi bioetanol. Analisis yang akan dilakukan pada penelitian ini adalah kadar selulosa baik di awal maupun di akhir pretreatment. Adapun metode chesson digunakan untuk menghitung kadar selulosa (Daffa, 1981).

Pada penelitian ini menggunakan Rancangan Acak Lengkap (RAL) faktorial antara lama pretreatment $(T)$ dan perbandingan massa bahan: volume pelarut $\mathrm{NaOH}(\mathrm{V})$. Faktor lama volume pretreatment $(\mathrm{T})$ terdiri 3 level (20, 30, dan 40 menit) dan faktor perbandingan massa bahan : volume pelarut (V) terdiri 3 level $(20 \mathrm{~g}: 150 \mathrm{~mL}, 20 \mathrm{~g}$ : $200 \mathrm{~mL}$ dan $20 \mathrm{~g}: 250 \mathrm{~mL}$ ) atau dengan penyederhanaan perbandingan massa bahan dan volume $(1: 7,5 ; 1: 10$; $1: 12,5)$ dengan pengulangan sebanyak 3 kali, sehingga akan didapatkan 27 kombinasi perlakuan, sedangkan untuk untreated (kontrol) atau tanpa perlakuan digunakan untuk perbandingan agar dapat diketahui perubahan parameter (selulosa) perlakuan, sehingga didapatkan total 30 sampel.

Bahan yang sudah dijadikan bubuk, digunakan sebanyak $20 \mathrm{~g}$ dan dicampur dengan larutan $\mathrm{NaOH}$ konsentrasi $0,5 \mathrm{M}$ dengan variasi volume yang telah ditentukan yaitu 150, 200, dan $250 \mathrm{~mL}$. Bahan dan $\mathrm{NaOH}$ dimasukkan ke dalam erlenmeyer dan ditutup menggunakan kapas dan aluminium foil untuk menghindari terjadinya penguapan yang tinggi. Setelah dicampur, sampel kemudian diberi perlakuan (pretreatment) gelombang microwave dengan waktu yang telah ditentukan yaitu 20, 30, dan 40 menit yang dimulai dengan suhu kamar.

Pretreatment dilakukan menggunakan oven microwave Panasonic model NN-GD371M dengan frekuensi $2450 \mathrm{MHz}$ dan daya 950 Watt. Pretreatment microwave menggunakan suhu pada level low temperature yaitu di bawah $100^{\circ} \mathrm{C}$. Parameter penelitian meliputi suhu, rendemen dan kandungan selulosa baik sebelum dan sesudah pretreatment. Kandungan selulosa diuji di Laboratorium Pusat Studi Ilmu Pangan dan Gizi Universitas Gadjah Mada Yogyakarta. Setelah data didapat dilakukan analisis menggunakan metode analisis ragam dua arah atau Two Way ANOVA (Two Way Analysis of Variance). Apabila setelah dianalisis menggunakan ANOVA terdapat beda nyata maka akan dilanjutkan uji jarak berganda atau DMRT (Duncant Multiple Range Test) dengan taraf nyata $5 \%$.

\section{HASIL DAN PEMBAHASAN}

\section{Efek Pretreatment Microwave-NaOH terhadap Kandungan Selulosa Tepung (Gedebog) Pisang Kepok}

Tiga bagian penting dari lignoselulosa ini yang paling penting untuk bahan baku bioetanol adalah selulosa, karena selulosa merupakan bagian rantai panjang dari gula, yang mana gula adalah substrat utama untuk dikonversi oleh bakteri sebagai sumber karbon dalam proses fermentasi menghasilkan bioetanol. Sehingga pretreamentmerupakan proses awal untuk memisahkan dan sekaligus mendapatkan selulosa dari polimer lain (hemiselulosa dan lignin). Jika selulosa sudah didapatkan maka bagian ini bisa masuk proses selanjutnya yaitu hidrolisis, yang bertujuan untuk memecah ikatan selulosa menjadi bentuk yang lebih sederhana yaitu gula. Metode hidrolisis banyak dipakai dengan memanfaatkan katalis kimia dan biologis. Gula hasil hidrolisis masuk proses selanjutnya yaitu fermentasi menjadi bioetanol.

Pretreatment yang dimanfaatkan untuk produksi etanol ini menggunakan dua faktor, yaitu antara waktu pretreatment dan volume pelarut $\mathrm{NaOH}$, parameter terpenting dalam penelitian ini adalah selulosa dengan satuan $\mathrm{mg} / \mathrm{g}$. Pretreatment ini menggunakan metode microwave dan pelarut $\mathrm{NaOH}$ 0,5 M. Adapun bahan baku yang dipakai adalah tepung (gedebog) pisang kepok yang telah diseragamkan ukurannya yaitu 60 mesh. Rata-rata yield selulosa (dalam satuan $\mathrm{mg} / \mathrm{g}$ ) pada penelitian ini ditampilkan pada Gambar 1.

Bahan tanpa perlakuan pretreatment sebagai kontrol menunjukkan nilai selulosa sebesar $472,4 \mathrm{mg} / \mathrm{g}$ dari $\mathrm{mg}$ selulosa per $\mathrm{mg}$ lignoselulosa. Jika dibandingkan dengan semua hasil perlakuan maka terlihat pola penurunan. Hal ini diduga selulosa yang telah terlepas dari struktur lignoselulosa terdegradasi menjadi gula. Menurut Sun dan Cheng (2002), hidrolisis untuk memecah ikatan dan menghilangkan kandungan hemiselulosa dan lignin serta merusak dari struktur selulosa sehingga menjadi gula sederhana. Bakteri $P$. chrysosporium mampu mengkonversi lignoselulosa yang ditandai penurunan kandungan penyusun lignoselulosa dan peningkatan gula pereduksi (Surthikanthi dkk., 2005). Lignin dikonversi oleh $P$. chrysosporium menjadi unit penyusunnya yaitu lignol. Selulosa menjadi gula heskosa yaitu glukosa, sedangkan hemiselulosa dikonversi menjadi gula pentosa, asam heksorunat dan sedikit gula heksosa. 


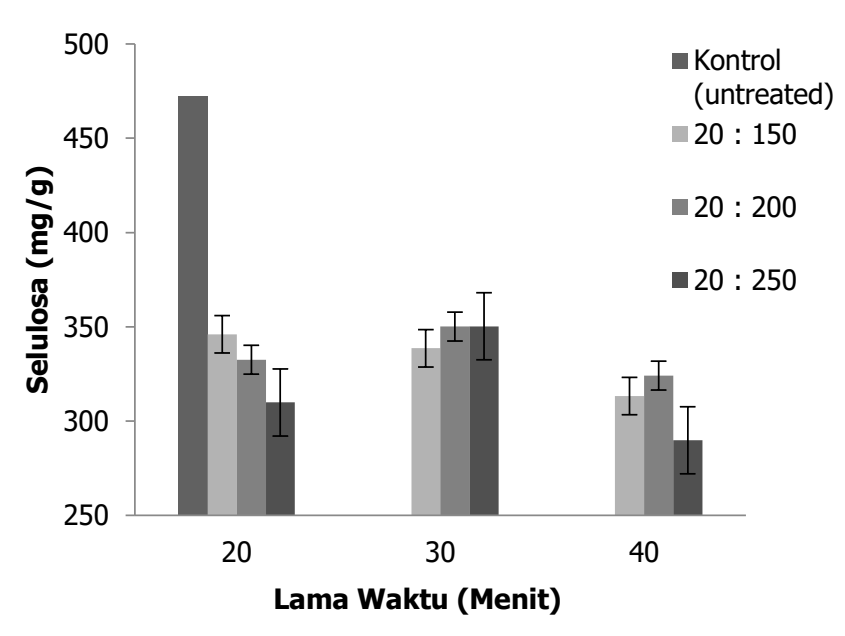

Gambar 1. Kandungan selulosa tepung (gedebog) pisang kepok pada variasi waktu dan perbandingan massa dengan volume pelarut

Berdasarkan hasil analisis ragam (Annova) bahwa $\mathrm{F}$ hitung perlakuan $\mathrm{T}$ (waktu pretreatment) lebih besar dari pada $F$ tabel $5 \%(3,58>3,55)$. Sehingga dapat disimpulkan bahwa perlakuan $\mathrm{T}$ (waktu pretreatment) berbeda nyata atau memberikan pengaruh yang signifikan terhadap kandungan selulosa. Adapun $\mathrm{F}$ hitung perlakuan $\mathrm{V}$ (volume pelarut) lebih kecil dari pada $\mathrm{F}$ Tabel $5 \%(1,06<3,55)$. Artinya perlakuan $\mathrm{V}$ (volume pelarut) tidak berbeda nyata atau tidak memberikan pengaruh yang signifikan terhadap kandungan selulosa. Adapun $\mathrm{F}$ hitung interaksi perlakuan TV juga lebih kecil dari pada $\mathrm{F}$ tabel 5\% $(0,64<2,51)$, bahwa interaksi perlakuan TV tidak berbeda nyata atau tidak memberikan pengaruh yang signifikan terhadap kandungan selulosa. Karena hanya perlakuan $\mathrm{T}$ (waktu pretreatment) yang berbeda nyata, maka uji lanjut menggunakan uji BNT 5\% hanya dilakukan pada perlakuan $\mathrm{T}$ (waktu pretreatment). Kesimpulan dari hasil uji BNT adalah, apabila perlakuan diikuti oleh huruf yang sama maka perlakuan tidak berbeda nyata. Sebaliknya, apabila perlakuan diikuti oleh huruf yang berbeda, maka perlakuan berbeda nyata. Adapun kesimpulan hasil uji BNT dapat dilihat pada Tabel 1. Semakin lama pretreatment maka semakin besar persentase penurunan kandungan selulosa tepung (gedebog) pisang kepok.

Tabel 1. Kandungan selulosa hasil pretreatment tepung (gedebog) pisang kapok

\begin{tabular}{cc}
\hline Perlakuan waktu (menit) & Kandungan selulosa $(\mathrm{mg} / \mathrm{g})$ \\
\hline Kontrol & 472,48 \\
20 & $329,47^{\mathrm{ab}}$ \\
30 & $346,33^{\mathrm{b}}$ \\
40 & $309,07^{\mathrm{a}}$ \\
\hline
\end{tabular}

Delignifikasi dilakukan untuk menghilangkan lignin yang dapat menghambat proses hidrolisis selulosa oleh mikroba dan dapat dilakukan menggunakan larutan alkali, seperti $\mathrm{NaOH}$. Lignin termasuk polimer fenol yang terdapat dalam dinding sel tumbuhan dan berikatan kuat dengan selulosa untuk membentuk lignoselulosa. Lignin bisa dikurangi atau dihilangkan dengan perlakuan alkali $\mathrm{NaOH}$ yang akan membentuk garam fenolat yang larut air. Apabila garam fenolat terbentuk maka ikatan selulosa dan lignin akan lepas sehingga diperoleh selulosa dalam keadaan bebas lignin (Rosdiana dkk., 2013).

Menurut Asnetty (2007), selulosa dan selulosa asetat akan terdegradasi dan mengakibatkan yield produk menurun jika suhu tinggi, waktu yang lama serta jika jumlah pelarut terlalu besar karena akan mempengaruhi kemungkinan tumbukan antar reaktan sehingga memperkecil yield produk. Pada hasil penelitian, waktu yang tidak terlalu cepat dan tidak terlalu lama yaitu 30 menit menghasilkan yield selulosa tertinggi. Hal ini dapat terjadi diduga waktu 30 menit adalah waktu optimal. Karena jika waktu pretreatment kurang lama maka untuk proses perusakan sel lignoselulosa tidak maksimal. Namun jika waktu pretreatment terlalu lama maka selulosa yang sudah terlepas dari lignoselulosa akan terjadi pemutusan rantai panjang selulosa oleh pelarut dan panas. Gelombang microwave yang mengenai gedebog pisang kepok telah merusak strukturnya akibat adanya rotasi dipol dan efek pelarut $\mathrm{NaOH}$ (Natrium Hidroksida) berinteraksi dengan bagian lignoselulosa yang bersifat fenolik, sehingga ikatan lignoselulosa akan terlepas (Rosyidin dkk., 2015).

Pada penelitian ini, semua perlakuan mengalami penurunan dengan kondisi terendah terdapat pada perlakuan 40 menit dengan volume $250 \mathrm{~mL}$. Yield selulosa terendah terdapat pada perlakuan waktu terlama (40 menit) jika dibandingkan dengan perlakuan yang lain. Sehingga diduga waktu paling lama pretreatment dapat mengakibatkan selulosa terdegradasi paling banyak. Namun yield selulosa ini berbeda dengan penelitian Dehani (2013) bahwa pada perlakuan pretreatment jerami padi dengan ukuran 100 mesh dan waktu 40 menit dengan metode microwave$\mathrm{NaOH}$ menghasilkan yield selulosa tertinggi. Perbandingan penelitian pretreatment terhadap yield selulosa yang berbeda ini diduga karena bahan berbeda sehingga sifat dan karakteristik material bahan yang membentuk rantai polimer biomasa juga berbeda, meskipun dikenai perlakuan pretreatment yang sama, serta ukuran luas permukaan juga dapat mempengaruhi dinamika perpindahan panas dan reaksi kimia sehingga mempengaruhi kekuatan ikatan polimer yang mudah diputus. Menurut Goenadi dkk. (1994) dalam Surthikanthi dkk. (2005), bahwa umur tumbuhan dan lokasi pengambilan sampel berpengaruh terhadap kandungan lignin.

Pelarut yang digunakan pada penelitian ini adalah Natrium Hidroksida atau $\mathrm{NaOH}$. Pelarut ini termasuk alkali basa kuat dan jika dilihat pada tabel periodik alkali $\mathrm{Na}^{+}$ini memiliki sifat paling reaktif dalam melepas ion positif. Dampaknya $\mathrm{NaOH}$ akan bereaksi ketika bertemu dengan material reaktif lain seperti lignin yang bersifat fenolik. Menurut Yoshikawa dkk. (2014), bahwa lignin merupakan polimer dengan berat molekul tinggi yang 
terdiri dari unit alkylphenolmethoxylated dan dapat dianggap sebagai sumber yang kaya fenol. Reaksi penukaran ion positif antara $\mathrm{Na}^{+}$dengan lignin akan mengakibatkan lignin meninggalkan ikatannya dari lignoselulosa dan akan diikuti pemutusan ikatan hemiselulosa karena bersifat lebih rapuh dibanding polimer yang lain sehingga selulosa juga ikut dapat terlepas.

\section{Hubungan Perlakuan Lama Pretreatment dan Perbandingan Massa Bahan dengan Volume Pelarut terhadap Suhu Pemanasan Pretreatment}

Pengukuran suhu pretreatment untuk delignifikasi dan mempertahankan selulosa dilakukan untuk mengetahui suhu yang terjadi di masing-masing perlakuan antara variasi perlakuan waktu dan variasi volume pelarut. Pada Gambar 2 menunjukkan pengaruh antara waktu dan perbandingan massa bahan dengan variasi volume pelarut berpengaruh pada fluktuasi rata-rata suhu pada masing-masing perlakuan. Semakin besar volume pelarut maka suhu semakin turun. Hal ini dapat dilihat pada perlakuan pada semua waktu. Misal pada waktu 40 menit suhu semakin turun dari volume terkecil $(150 \mathrm{~mL}) \mathrm{ke}$ terbesar $\left(250 \mathrm{~mL}\right.$ ) yaitu suhu $89^{\circ} \mathrm{C}, 85,30^{\circ} \mathrm{C}$, dan 78,30 ${ }^{\circ} \mathrm{C}$. Hal ini diduga karena semakin luasnya perpindahan panas oleh semakin banyaknya volume pelarut sehingga panas yang terjadi juga lebih lama tinggi. Kemudian jika dilihat dari waktu, suhu akan semakin tinggi seiring bertambahnya waktu pada semua perlakuan variasi volume pelarut. Misal pada volume $250 \mathrm{~mL}$ mulai pada waktu 20 menit suhu akan naik dari $55,3^{\circ} \mathrm{C}, 70^{\circ} \mathrm{C}$, dan $78,30^{\circ} \mathrm{C}$.

Perpindahan panas yang terjadi pada penelitian ini menggunakan microwave. Pada penelitian ini, panas dari generator microwave menghasilkan gelombang microwave yang dipancarkan langsung mengenai bahan (tepung pisang (gedebog) kapok), kemudian panas merambat ke seluruh bahan dan pelarut $\mathrm{NaOH}$. Perpindahan panas ini mengakibatkan suhu bahan akan semakin naik jika waktu semakin lama, begitu pula semakin sedikit volume pelarut $\mathrm{NaOH}$.

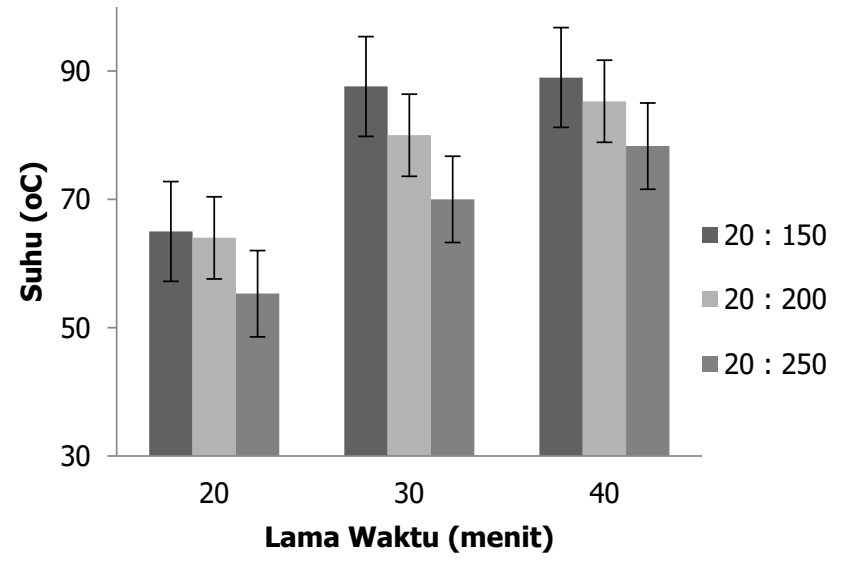

Gambar 2. Hubungan lama pretreatment dan perbandingan massa dengan volume terhadap suhu pemanasan pretreatment

\section{Hubungan Perlakuan Lama Pretreatment dan Perbandingan Massa Bahan dengan Volume Pelarut terhadap Rendemen}

Penghitungan rendemen dilakukan untuk mengetahui efektivitas dan kecermatan penelitian. Pada penelitian ini menggunakan faktor waktu dan perbandingan massa bahan: volume pelarut yang berbeda-beda yaitu 20, 30, dan 40 menit serta perbandingan massa bahan dengan volume pelarut 20:150, 20:200 dan 20:250 (g:mL). Penghitungan rendemen ini menggunakan rumus berat kering akhir penelitian dibagi dengan berat kering sebelum pretreatment yang kemudian dikalikan 100 persen. Berat kering bahan merupakan hasil bahan sampel pretreatment setiap perlakuan yang sudah dikurangi berat kadar airnya.

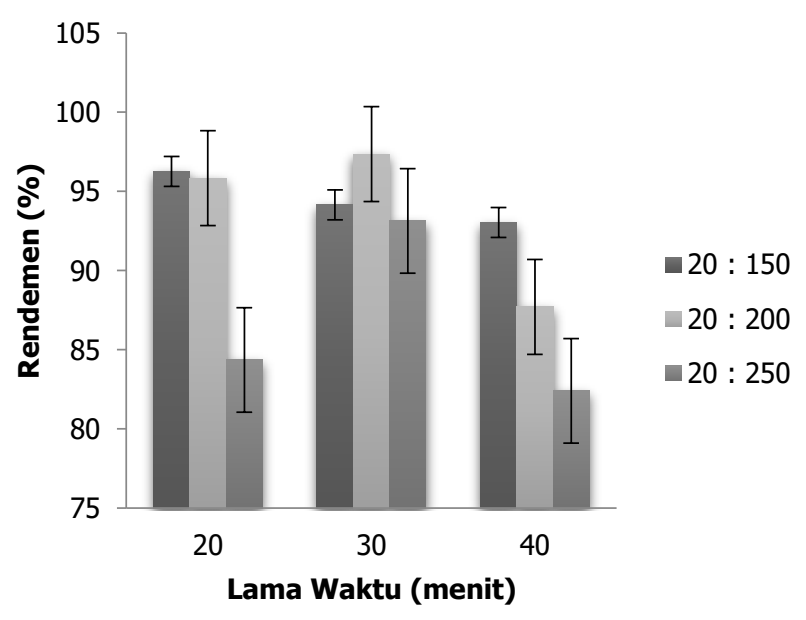

Gambar 3. Hubungan lama pretreatment dan perbandingan massa dengan volume terhadap rendemen

Rata-rata rendemen penelitian ditunjukkan pada Gambar 3. Rata-rata rendemen pada perlakuan volume $250 \mathrm{~mL}$ selama 20 menit yaitu $84,30 \%$, pada waktu 30 menit memiliki rata-rata rendemen $93,10 \%$, dan pada waktu 40 menit memiliki rata-rata rendemen $82,40 \%$. Kemudian pada perlakuan volume $200 \mathrm{~mL}$ dengan waktu 20 menit memiliki rata-rata rendemen $95,80 \%$, pada waktu 30 menit memiliki rata-rata rendemen $97,30 \%$, dan waktu 40 menit memiliki rata-rata rendemen $87,70 \%$. Kemudian pada perlakuan volume $150 \mathrm{~mL}$ dengan waktu 20 menit memiliki rata-rata rendemen $96,20 \%$, pada 30 menit memiliki rata-rata rendemen $94,10 \%$ dan rata-rata rendemen pada waktu 40 menit yaitu $93 \%$. Penelitian ini terdapat rendemen tertinggi yaitu pada perlakuan waktu 30 menit dan volume pelarut $200 \mathrm{~mL}$ yaitu $97,30 \%$. Sedangkan rendemen terendah terdapat pada perlakuan waktu 40 menit dan volume pelarut $250 \mathrm{~mL}$ yaitu $82,40 \%$.

\section{Perlakuan Terbaik}

Pada Tabel 2 menjelaskan bahwa penelitian ini didapat dua perlakuan terbaik dari rata-rata selulosa dalam satuan $\mathrm{mg} / \mathrm{g}$ tertinggi yaitu pada perlakuan waktu 30 menit dengan volume pelarut $250 \mathrm{~mL}$ menghasilkan 
yield selulosa sebesar $350,20 \mathrm{mg} / \mathrm{g}$ serta dengan rendemen rata-rata sebesar $93,10 \%$.

Tabel 2. Pemilihan perlakuan terbaik

\begin{tabular}{cccc}
\hline Perlakuan & $\begin{array}{c}\text { Rendemen } \\
(\%)\end{array}$ & $\begin{array}{c}\text { Selulosa } \\
(\%)\end{array}$ & $\begin{array}{c}\text { Selulosa } \\
(\mathrm{mg} / \mathrm{g})\end{array}$ \\
\hline Kontrol (untreated) & 100,00 & 47,24 & $472,48 \pm 7,08$ \\
$20: 250,30$ menit & $93,10 \pm 3,93$ & 37,62 & $350,28 \pm 15,83$ \\
\hline
\end{tabular}

Yield selulosa dalam satuan $\mathrm{mg} / \mathrm{g}$ pada penelitian ini menunjukkan penurunan massa, sama halnya dengan penurunan rendemen dari kontrol. Hal ini terjadi diduga karena adanya proses pretreatment yang berlanjut reaksi degradasi selulosa menjadi gula-gula sederhana. Karena pretreatment ini menggunakan perlakuan panas dan alkali basa kuat serta berlangsung lama. Selain itu terjadi massa yang hilang pada proses penyaringan sehingga material-material yang bersifat larut air akan lolos dari kertas saring seperti gula sederhana dan hemiselulosa. Maka dari itu, penelitian ini tidak melakukan proses penetralan menggunakan air/aquadesh yang berguna untuk menetralkan pH bahan. Karena hal ini akan mempengaruhi hasil yield rendemen serta tujuan dari pretreatment adalah fokus pada yield selulosa. Namun apabila selulosa diproses lebih lanjut pada proses hidrolisis dan fermentasi atau gabungan keduanya maka pH selulosa perlu dinetralkan atau sampai batas tertentu agar pertumbuhan bakteri hidrolisis dan bakteri fermentasi tidak terganggu pada suasana $\mathrm{pH}$ yang tinggi.

\section{Perbandingan dengan Metode dan Bahan Baku Lain}

Perbandingan perubahan kandungan selulosa dengan metode dan bahan baku lain dapat dilihat pada Tabel 3 . Penggunaan microwave mengakibatkan penurunan kandungan selulosa kecuali pada bahan baku eceng gondok. Persentase penurunan kandungan selulosa pada tepung (gedebog) pisang kepok lebih rendah dibandingkan Chlorella vulgaris dengan microwave- $\mathrm{NaOH}$ pretreatment. Selain itu, penurunan kandungan selulosa pada tepung (gedebog) pisang kepok berukuran 100 mesh lebih rendah dibandingkan dengan 60 mesh

Tabel 3. Perbandingan persentase penurunan dan peningkatan selulosa pada beberapa metode pretreatment dan bahan baku

\begin{tabular}{|c|c|c|}
\hline Metode & Bahan & $\begin{array}{l}\text { Perubahan } \\
\text { selulosa }\end{array}$ \\
\hline \multicolumn{3}{|l|}{ Microwave- $\mathrm{NaOH}$} \\
\hline $\begin{array}{l}\text { pretreatment (Singh dkk., } \\
\text { 2014) }\end{array}$ & Jerami padi & Turun $1,46 \%$ \\
\hline Alkalisasi resistive heating & & \\
\hline $\begin{array}{l}75^{\circ} \mathrm{C} ; \mathrm{NaOH} 0,07 \mathrm{M} \\
\text { (Maharani dkk., 2017) }\end{array}$ & Jerami padi & Naik $8,88 \%$ \\
\hline $\begin{array}{l}\text { Microwave-NaOH } 2 \text { M; } 30 \\
\text { menit (Elwin, 2014) }\end{array}$ & Eceng gondok & Naik $21,91 \%$ \\
\hline $\begin{array}{l}\text { Microwave-NaOH 0,7 M; } 40 \\
\text { menit (Siregar, 2015) }\end{array}$ & Chlorella vulgaris & Turun $58,27 \%$ \\
\hline $\begin{array}{l}\text { Alkaline explosion } 150^{\circ} \mathrm{C} ; 4 \\
\text { bar; } \mathrm{NaOH} 2,5 \mathrm{M} ; 30 \text { menit } \\
\text { (Cahyono, 2015) }\end{array}$ & $\begin{array}{c}\text { Tandan kosong } \\
\text { kelapa sawit (TKKS) }\end{array}$ & Naik 96,57\% \\
\hline $\begin{array}{l}\text { Microwave-NaOH 0,5 M; } 40 \\
\text { menit (Rosyidin dkk., 2015) }\end{array}$ & $\begin{array}{l}\text { Tepung (gedebog) } \\
\text { pisang kepok } 100 \\
\text { mesh }\end{array}$ & Turun $14,50 \%$ \\
\hline $\begin{array}{l}\text { Microwave-NaOH 0,5 M; } 30 \\
\text { menit (hasil penelitian) }\end{array}$ & $\begin{array}{l}\text { Tepung (gedebog) } \\
\text { pisang kepok } 60 \\
\text { mesh }\end{array}$ & Turun $20,36 \%$ \\
\hline
\end{tabular}

walaupun dengan waktu yang lebih cepat. Metode terbaru alkalisasi resistive heating untuk pretreatment bioetanol mampu meningkatkan kandungan selulosa sekaligus menurunkan lignin (Maharani dkk., 2017). Semakin besar kandungan selulosa hasil pretreatment maka semakin besar pula glukosa yang nantinya dapat dikonversi menjadi bioetanol.

\section{KESIMPULAN}

Hasil penelitian dapat memberikan beberapa simpulan terkait proses pretreatment lignoselulosa dari tepung (gedebog) pisang kepok, seperti gelombang microwave memiliki pengaruh terhadap kandungan selulosa dari tepung (gedebog) pisang kepok pada proses pretreatment. Faktor volume pada penelitian memiliki pengaruh yang tidak berbeda nyata terhadap yield selulosa namun faktor perlakuan waktu memiliki beda nyata terhadap yield selulosa. Sedangkan pada penelitian didapatkan perlakuan terbaik yaitu pada waktu 30 menit dengan perbandingan massa bahan : volume pelarut $20 \mathrm{~g}$ : $250 \mathrm{~mL}$ mampu menghasilkan yield selulosa sebesar $350,20 \mathrm{mg} / \mathrm{g}$ serta memiliki rendemen $93,10 \%$.

\section{DAFTAR PUSTAKA}

Anindyawati, T. (2009). Prospek enzim dan limbah lignoselulosa untuk produksi bioetanol. BS, Vol. 44, No. 1, Juni 2009 : 49- 56.

Asnetty. (2007). Pengembangan proses pembuatan selulosa asetat dari pulp tandan kosong kelapa sawit proses etanol. Prosiding seminar nasional fundamental dan aplikasi teknik kimia. Institut Teknologi Sepuluh Nopember.

Cahyono, A. (2015). Penggunaan lindi hitam pada proses pretreatment tandan kosong kelapa sawit(Elaeis guineensis). Skripsi. Fakultas Teknologi Pertanian Universitas Brawijaya.

Daffa, R. (1981). Acidogenic Fermentation of Lignocelluse Acid Yild and Conmertian of Component Biotech-Bioeng, pL 2167-2170.

Dehani, F.R., Dwi Argo, B., \& Yulianingsih, R. (2013). Pemanfaatan iradiasi gelombang mikro untuk memaksimalkan proses pretreatment degradasi lignin jerami padi (pada produksi bioetanol). Jurnal Bioproses Komoditas Tropis. 1 (1): 13-20.

Elwin. (2014). Analisa pengaruh waktu pretreatment dan konsentrasi naoh terhadapkandungan selulosa, lignin dan hemiselulosa eceng gondok pada proses pretreatment pembuatan bioetanol. Skripsi. Fakultas Teknologi Pertanian Universitas Brawijaya. Malang.

Kardono, Broto, L.S., Sudiyani, Y., Idiyanti, T., Sudiyarmanto, \& Waluyo, J. (2010). Teknologi pembuatan etanol berbasis lignoselulosatumbuhan tropis untuk produksi biogasoline. Laporan Akhir Program Insentif Peneliti dan Perekayasa LIPI Tahun 2010. LIPI.

Maharani, D.M., Normalasari, L., Kumalasari, D., Prakoso, A.H., Kusumaningtyas, M., \& Ramadhan, M.T. (2017). Pengaruh Pretreatment Secara Alkalisasi-Resistive Heating Terhadap Kandungan Lignoselulosa Jerami Padi. Jurnal Agritech. Vol. 37, No 2, Mei 2017, 132-138. 
Prastowo, B., \& Richana, N. (2014). Biofuel generasi-1, generasi-2. Jakarta: IAARD Press.

Rasubala, Delfhia, Yuliviana, A., Retnoningtyas, E.S., \& Aylianawati. (2013). Pengaruh suhu dan waktu fermentasi bioetanol dari tongkol jagung dengan perlakuan awal steam explosion. Jurnal Teknik Kimia Indonesia. Vol. 11, No. 6, 2013, 283-292.

Rohmadi, N., \& Amalia, N. (2010). Pembuatan bioetanol dari ubi jalar putih. Laporan Tugas Akhir. Jurusan Teknik Kimia UNS. Surakarta.

Rosdiana, Noermala S., Sarjono, P.B., \& Mulyani, N.S. (2013). Aktivitas Fusarium oxysporum dalam Menghidrolisis Eceng Gondok (Eichhornia crassipes) dengan Variasi Temperatur. Chem Info. 2013. Vol 1, No 1, Hal $220-225$.

Rosyidin, K., Khaharudin, Y., Amin, R., Andriani, N.K., \& Maharani, D.M. (2015). Assisted Pretreatment with Microwave Heating untuk Peningkatan Kadar Selulosa Batang Pisang pada Produksi Bioetanol. Prosiding Simposium Nasional Inovasi dan Pembelajaran Sains (SNIPS). Juni 2015 : 33-36.

Seftian, D., Antonius, F., \& Faizal, M. (2012). Pembuatan etanol dari kulit pisang menggunakan metode hidrolisis enzimatik dan fermentasi. Jurnal Teknik Kimia. No. 1, Vol. 18, Januari 2012 : 10-16.

Singh, R., Tiwari, S., Srivastava, M., \& Shukla, A. (2014). Microwave assisted alkali pretreatment if rice straw for enchancing enzymatic digesbility. Journal of Energy. 2014 (2014): 1-7.

Siregar, M.R. (2015). Pengaruh konsentrasi $\mathrm{NaOH}$ dan lama waktu pemanasan microwave dalam proses pretreatment terhadap kadar lignoselulosa Chlorella vulgaris. Skripsi. Fakultas Teknologi Pertanian Universitas Brawijaya.

Sukaryo, B.J., \& Hargono. (2013). Pembuatan bioetanol dari pati umbi kimpul (Xanthasoma Sagittifolium). Momentum. Vol. 9, No. 2, Oktober 2013, Hal. 41-45.

Sukowati, A., Sutikno., \& Rizal, S. (2014). Produksi bioetanol dari kulit pisang melalui hidrolisis asam sulfat. Jurnal Teknologi dan Industri Hasil Pertanian. Volume 19, No.3 Oktober 2014.

Sun, Y., \& Cheng, J. (2002). Hydrolysis of lignocellulosic materials for ethanol production: a review. Bioresource Technol:: 83, 1-11.

Surthikanthi, D., Suranto, \& Susilowati, A. (2005). Biokonversi kompleks lignoselulosa eceng gondok (eichorrnia crassipes (martz)solms) menjadi gula pereduksi oleh Phanerochaete chrysosporium BioSMART. April 2005. Volume 7, Nomor 1. Halaman: 17-22.

Yoshikawa, T., Shinohara, S., Yagi,T., Ryumon, N., Nakasaka, Y., Tago, T., \& Masuda, T. (2014). Production of phenols from lignin-derived slurry liquid usingiron oxide catalyst. Applied catalysis b-environmental. 146: 289-29. 